\title{
Rearticulating E-dentities in the Web-based Classroom: One Technoresearcher's Exploration of Power and the World Wide Web
}

\author{
Amy C. Kimme Hea \\ University of Arizona, Tuscon, AZ 85721, USA
}

\begin{abstract}
This article argues that in order to be critical agents for change, web-based instructors must interrogate the contradictions and ambiguities of cultural narratives about the World Wide Web. Because cultural narratives of technology affect the possible range of instructor and student e-dentities, computer composition instructors must better understand, negotiate, and build strategies for creating more democratic learning environments in the web-based classroom. This article discusses a semester-long, articulatory study of web-based composition teaching at Purdue University. An identification, description, and analysis of the cultural narrative of the Web as a global village in relationship to participant instructors' classroom experiences demonstrates the challenge to create complex e-dentities in the computer classroom. This article suggests ways of rearticulating the role of the instructor as critical agent through contextualized teacher training.
\end{abstract}

(C) 2002 Published by Elsevier Science Inc.

Keywords: Articulation theory; Computer composition; Critical theory and practice; Teacher training; Web-based research; World Wide Web

\section{Introduction}

Web-based teaching is becoming an increasingly common practice for computer composition instructors. Many instructors design and publish their own web documents and ask students to work through whole class or personal home pages. Some instructors use the Web for email correspondence and chat space and MOO discussions. And still others encourage students to use the Web for research as a means to access library sources or to locate online materials.

Email address: kimmehea@u.arizona.edu (A.C. Kimme Hea). 
Although computer composition scholars have contributed to our understanding of the integration of web-based technologies (Gillette, 1999; Heba, 1997; O’Sullivan, 1999; Watkins, 1996) and student responses to such integrations (DeWitt, 1997; Pagnucci \& Mauriello, 1999; Schneider \& Germann, 1999; Takayoshi, Huot, \& Huot, 1999), more and continued research must focus on the composition instructor as critical agent in the web-based classroom. This research call has been emphasized in the work of Gail E. Hawisher and Cynthia L. Selfe (1991) and Cynthia L. Selfe (1999b) as they argue to educate both students and instructors to be critical users, producers, and critics of technology.

In this article, I assert that in order to be critical agents for change, web-based instructors must interrogate the contradictions and ambiguities of cultural narratives about the Web. Because cultural narratives of technology affect the possible range of instructor and student edentities, ${ }^{1}$ we must better understand, negotiate, and build strategies for creating more democratic learning environments in the web-based classroom. The following article represents just one "moment" of a more developed articulation project. Here, I discuss my semester-long study of web-based composition teaching at Purdue University. I identify, describe, and analyze one of the cultural narratives on the Web that participant instructors felt most affected their integration of web-based technology - the Web as a global village.

With the dual purpose of identifying the binaries fostered by specific web narratives and offering ways of challenging them, I employ articulation theory as my research methodology. Articulation not only allows me to engage the web-based technologies from a critical standpoint but also provides me with the means to critically interact with participants. Using this framework, I connect instructor experiences to the cultural narrative of the Web as a global village and analyze the ways that this narrative affected the instructors' abilities to create nondeterministic edentites in the web-based classroom. In closing, I propose contextualized teacher training as a way of rearticulating the role of the instructor as critical agent. By combating deterministic narratives and supporting instructors in developing their own complex edentities, such training enables instructors to help students to do so as well.

\section{Articulating a critical and flexible methodological framework}

In exploring the connections among the cultural discourses and practices that shape our understanding of the Web, I faced a particular challenge to enact a methodological framework that is both critical and flexible. Critical technology theorists assert that technology is more than simply a neutral tool that is universally adaptable to our needs. Rather, technology has historical and cultural significance that is constructed through and by our cultural definitions of "acceptable" uses of technology (Feenberg, 1991, 1995a, 1995b, 1999; Haraway, 1985, 1995, 1997; Latour, 1992, 1993). The web-based techno-researcher, then, must not only offer insight into the cultural implications of her data but do so knowing all the while that those sources - web pages that help to structure her own and instructor participant experiences - can be taken down, completely revised, or moved to a new location. To meet these challenges and still work through the complex layers of my project, I turned to articulation theory.

With its history in the critical tradition, articulation theory requires its practitioners to acknowledge the dynamic, multiple, and contingent nature of all power relations (Deleuze \& 
Guattari, 1987; Grossberg, 1992; Hall, 1985, 1986, 1989; Laclau, 1977; Laclau \& Mouffe, 1985; Slack, 1989, 1996). To understand the complexity of power relations, Stuart Hall (1985) calls for "double articulation" or as his definition posits, the acknowledgment that "the structurethe given conditions of existence, the structure of determinations in any situation-can also be understood, from another point of view, as simply the result of previous practices" (p. 95). In other words, looking at the "normalized" ways we incorporate the Web into our classrooms can help us uncover underlying expectations and values associated with the roles of web-based technology, literacy, student-student and student-instructor relationships. Moreover, by identifying and complicating how our experiences with the Web are related to constructions of gender, class, race, ethnicity, religion, age, and sexuality, we can open up spaces for edentities that encourage more equitable practices.

The process of establishing new practices and intervening in constructedness of power relations is termed "rearticulation." 2 To productively seek out equitable ways of deploying web-based technologies and even to create a methodology that actively engages the research participants, I worked with instructors to understand the cultural forces at play in their teacherly lives. In his articulation project on hypertext, Johndan Johnson-Eilola (1997a) pointed to the significance of pursuing such articulatory research as he argued:

admitting the ideological nature of our teaching should make us become interested in the ways in which hypertext can be rearticulated to a more explicitly social activity, a way of providing multiple mappings that do not purport to be mere (innocent) reflections of society, but explicitly political ways to live society and change it. (p. 178)

Articulation theory, according to Johnson-Eilola, requires more than a critique of hypertext or any particular technology for that matter. Rather, articulation asks us as teachers, scholars, mentors, and technology users to invest in the development of critical teaching and learning practices. In the following research description, my interpretations and instructor feedback are integrated to develop a more complex picture of the ways cultural narratives on the Web affect our range of possible edentities. This articulation is created with the hope of rearticulating those positionalities.

\section{Engaging the instructor participants}

As co-mentors of computers and composition at Purdue University, my colleague Melinda Turnley $^{3}$ and I helped first-year writing instructors integrate technology into their pedagogies. Offered as a graduate-level, one-credit hour course, English 502I: Computer Composition Mentoring includes presemester and weekly mentor meetings concurrent with the instructors' new roles as computer compositionists. During the fall 1999 semester when I conducted this study, I continued to mentor in the program, but I did not assign the course grades of $P$ (Passing) or NP (Not Passing). After explaining my research project and role in the mentoring, four of the six members in the group agreed to participate in this project. Because of a family crisis, one instructor dropped from the research in the third week of the semester. The remaining three instructors are represented in this article under their self-selected pseudonyms of Kris, Elizabeth, and Sam. ${ }^{4}$ 
Throughout this project, I have employed a dialogic research design (Lather, 1991) that invites the instructors to engage in and enrich the research process itself. This sharing included gathering a wide range of data: two interviews ${ }^{5}$ (one in the beginning of the semester and another at the end); two teaching observations; two technology-ranking exercises ${ }^{6}{ }^{\text {and }}$ teaching materials ${ }^{7}$ developed by the instructors. These contributions provided us with a starting point to reflect on their classroom interactions with students. During their interviews, all the instructors attested that they were striving to be critical agents of technology and that their web-based materials were designed with that goal in mind. Instructors also framed their course plans for my invited visits to their classrooms to help me both identify the ways they were enacting a critical technological philosophy and record the ways that students in their courses interpreted certain critical approaches. Further, my write-up of data and reports as well as drafts of this article were provided to the instructors for their feedback and insights.

\section{Native, other, and the global village: instructor negotiations of the Web}

In her discussion of the narrative of the global village in relationship to technology advertisements, Selfe (1999a) explains the ways this narrative is revised to include the companion narrative of the "electronic colony" in which "the global village retains its geographical reach, but it becomes a world in which different cultures, different peoples, exist to be discovered, marveled at - in a sense, known and claimed by - those who can design and use technology" (p. 295). Her explication of these companion narratives is useful in thinking about the web-based classroom experiences of instructors in this study. They, too, find themselves discussing issues of technology as related to $u s$ versus them categories. The $u s$ is sometimes defined as those of us in web-based classrooms, and them includes persons not online or not interested in being online. At other times, however, the instructors find students themselves creating a culture of us and them within the classroom where the "high-tech" students are viewed as "soon-to-be competitors" in the growing global marketplace and their "low-tech" peers are constructed as "technological underdogs" trying to catch up. In other classroom moments, edentites are constructed with technology representing the white, male, and upwardly mobile professional. This construction leaves women and people of color and of lower class status "behind" in the electronic world. These underrepresented groups are believed to be unable to master the Web and deploy it as it should be deployed - to achieve economic gain and intellectual freedom. Despite their experiences with such divisions and elisions, the instructors and students still found themselves largely influenced by and struggling with cultural narratives that claim technology has an inherent value in and of itself and that equal participation with the Web is guaranteed to all.

\subsection{Kris's negotiation of the Web as a global village}

Kris's course materials and our discussions about his teaching revealed a focus on directly challenging the narrative of the Web as a global village. Kris mentioned in his first interview with me that the Web is a "window to culture for cultural critique" (personal interview, Oct. $5,1999)$. To make technology use and critique central themes of his pedagogy, Kris selected 
Cyberspace: Identity, Community, and Knowledge in the Electronic Age by Richard Holeton as his course textbook. Kris described the class on his course web page:

Through a variety of readings, students will explore and discuss three main facets of our so-called "global village": identity, community, and knowledge. We will not only discuss and examine the many ways in which computers are affecting these three areas of our lives, but we will also use the computers as we examine their impact, or lack of impact on our lives. (online, 1999)

In other words, students used course technologies to both develop assignments and examine social and cultural conceptions of technology, particularly the Web.

During my first classroom visit to Kris's course, I watched him carefully lead students through a series of readings and web sites related to the idea of the Web as a global village. The level of interaction among Kris and students in his class allowed for valuable insights into the way this cultural narrative impacts the range of potential edentities. During the first part of class, students developed definitions of the "global village" for persons who might not understand the metaphor. This exercise was situated in relationship to a brief discussion of oxymorons where students brainstormed to come up with the definition as "a contradiction in terms." It was evident from Kris's interactions with students that he wanted them to share definitions and understandings of terms used in the class. After student teams completed the task of defining the global village, Kris asked them to list their definitions on the white board so that the whole class could discuss the definitions in relationship to a cartoon and web site.

The list of student definitions of the global village included the following:

- The world viewed as a community in which distance and isolation have been dramatically reduced by electronic media,

- The world as a small community,

- A collection of individuals around the world linked through a common communication media, the Internet,

- The global village is a place where people communicate on common topics anywhere in the world. Where the place they meet doesn't exist in the real world but is a fictitious place created by the users, and

- The global village is a view of the world in which all people are in constant communication and can discuss issues pertaining to the whole world. (class observation, Aug. 22, 1999)

Kris and students in his class discussed these definitions by relating them to a cartoon depicting the "Information Superhighway" as an entrance ramp to the interstate labeled "Global Village": One of two shadowed figures under the highway explained, "I didn't have the training and I couldn't afford the computer, software and modem." They also related their definitions to a web site containing "world-o-meters" that calculate statistics on birth rate, death rate, and other global factors (see Figure 1).

Kris posed two questions for student consideration in looking at the cartoon and web site: (1) Is the depiction in the cartoon an accurate one? and (2) Why does such a web page exist? (class observation, Aug. 22, 1999). It was easy to see that Kris was attempting to complicate their definitions and provide other material to challenge the contradictions inherent in the "global village" metaphor. 


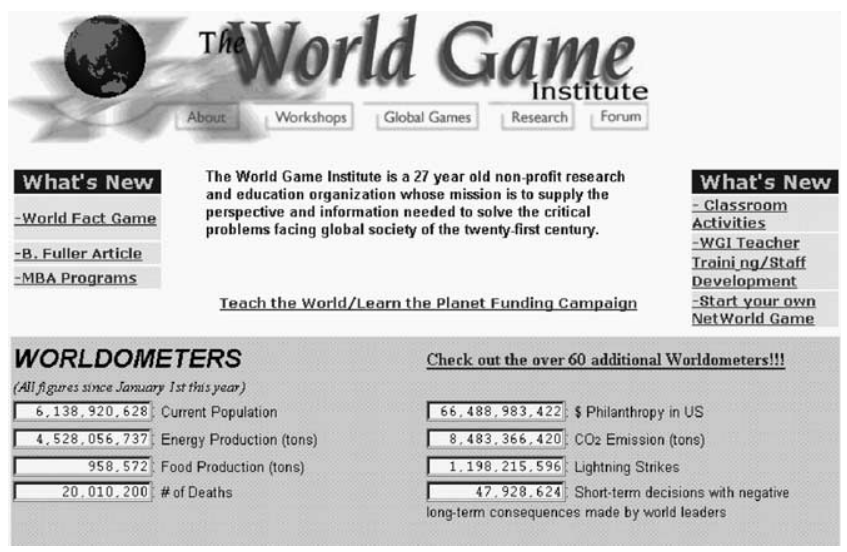

Fig. 1. The World Game Institute's world-o-meters at <http://www.worldgame.org/worldometers/>.

As the discussion unfolded, however, Kris found that student responses to his questions and concerns were reduced to less subtle discussions about "have" or "have not." This binary was expressed in student comments that ranged from "the image is just a joke" to "some people choose to be stuck under the bridge like Aboriginal peoples. Their world suits them just fine. They don't need what we have anyway." Kris asked students to consider the oxymoron of the global village but discovered that for students-whose access to the Web is ensured, particularly by its physical presence in their daily lives-technology access is defined by the physical presence of hardware, software, and networks. They were not compelled to explore more subtle connections among access and race, class, ethnicity, gender, sexuality, or age.

In fact, when ethnicity came up in the discussion, it was defined in rather stereotypical ways such as "we [members of this class] don't need to talk about Africa or Australia," assuming that these entire continents do not have access to the Internet and do not necessarily need it either. For the most vocal students, technology access was reserved for those who employ it for economic and social gain. Their determinism played out in their comments about the cartoon and the web page. Their definitions, which Kris diligently attempted to complicate, went unchallenged because many could only see the benefits of technology, the Web, and Internet in their daily lives, and even students sensitive to the technology disparities saw the technologies as an either/or proposition-either you have access, or you do not.

Kris's efforts to complicate the metaphor of the global village were well planned and supported by readings, cartoons, web pages, and other past discussions he had with students in the course, but the narrative of the global village and the Web as a virtual melting pot were stronger than his own well-fashioned pedagogical attempts to complicate this deterministic view of technology. Slipping back and forth between the idea of the Web as a means to connect to the "world" and the concern that not everyone needs to connect to the Web led the discussion to the forgone conclusion that those with access to web technologies are somehow more deserving and more capable technology users than those without access.

These conclusions are suggested by Kris's comments about a ranking exercise where he circled " 8 " for his theoretical commitment to critical theories of technology and " 6 " for his 
ability to instantiate that commitment. When I asked him to reflect on his rankings, Kris responded that

I think with any theoretical commitment getting it to actually happen in the classroom is difficult.... It is difficult on an ideal basis to work your theoretical commitment to critical views of technology into your daily classroom plan where you have new technologies that you have to use, and students are new to this technology. You have things that you need to get done in your writing class, so staying committed to these critical views on a daily basis can be difficult. (personal interview, Dec. 13, 1999)

Kris's comments express the technology teaching challenges of not only an instructor new to teaching in a computer environment but also instructors experienced in such environments. As Charles Moran (1998) argued in his self-study, "the presence of computers in a writing classroom does make a difference, that technologies are not transparent, and that the change in moving from a traditional classroom to a computer classroom (or back!), is substantial" (p. 9). Kris and the other instructors in my study echo these sentiments as they wrangled with the practical/theoretical split and with their desires to complicate the web-based technologies at the same time they were employing those technologies in their teaching practices.

\subsection{Elizabeth's negotiation of the Web as global village}

The metaphor of the Web as a global village was prevalent in Elizabeth's class as well. Much like Kris's pedagogical focus on technology as a resource and topic for critique, Elizabeth created a pedagogy that sought to complicate constructions of online communities. In her first interview with me, she explained that "my students use the Web to work with online communities. Most of them chose online communities whether they were chatrooms or web message boards or Usenet. They also tend to use the Web to do their research" (personal interview, Oct. 5, 1999). Elizabeth encouraged students to explore the idea of community by developing two projects related to online, web-based communities. The first assignment was described on her course web page as "exploring and explaining an online community" (online, 1999). Students were encouraged to develop essays that questioned how their chosen online communities "become" communities. She asked students to think about the shared language and values of the communities and how those were demonstrated in the communities' interactions. The second assignment was described on Elizabeth's course web page as "evaluating an online community." This assignment asked students to "explore how your online community creates knowledge and how it decides what knowledge is "valuable' and 'accurate"' (online, 1999). Both of these essay assignments required students to familiarize themselves with a chatroom, MOO, Usenet group, or newsgroup of some kind. In her development of the assignments, Elizabeth carefully constructed web-based technologies as "social" technologies_ones that reflect human interactions and understandings.

Her commitment to critical interactions with these online communities, however, was all but thwarted, as were Kris's, by "global" constructions of web-based interactions. Students exploring these communities assumed the status of "observer" often as it is defined in more scientistic research models. Elizabeth's suggestion that students could "lurk" was misconstrued as an invitation to "see" the participants in the online space as "others." This sense of division 
allowed students to take on edentities that ignored certain connections between the online community members and themselves. In terms of technical expertise, students who had not been members of the online group that they were studying prior to the assignments were also more likely not to have been members of any online community before the course. Thus, students were invested in "seeing" the differences between themselves and their participants as a difference in technological expertise - the participants had the "high-tech" skills and language to reflect their membership in the group, and the students did not.

In discussing student responses to the online communities assignments, Elizabeth expressed her sense of frustration that "students seem to take it [the Web] for granted-it is what it is. When I ask them to think about the Web and what happens there, they assume that it is "just the way it is" (personal interview, Dec. 13, 1999). This lack of critical awareness created a space where students wrote the other into their projects. At once, the online communities were other and rationalized as part of the Web phenomenon of the global village. In my estimation, and Elizabeth's as well, students could other the participants in the online communities because the Web is the totalizing and equalizing factor across the different groups being studied.

Despite Elizabeth's desire to develop students' critical thinking about online communities, students subverted more complex constructions of online spaces by interpreting their experiences through cultural narratives of the Web. For example, rather than complicating the ideas of gender represented by the "women's Web" and web sites like <http://iVillage.com> (see Figure 2) and <http://www.women.com>-where "modern" women can swap recipes, get career advice, and exchange stories about children and spouses as well as log into discussion groups on soap operas and astrology-students rationalized these uses of the Web through the narrative of inclusion developed by the global village stories. ${ }^{8}$ Without a complex understanding of gender representations on the Web, as described in Gail Hawisher and Patricia Sullivan's (1999) study, the students defended the position that the Web is inclusive based upon the specialized sites they examined. Such inclusion stories of the Web disregard broader and more significant concerns about the "norming" of the Web and offer instead the idea that

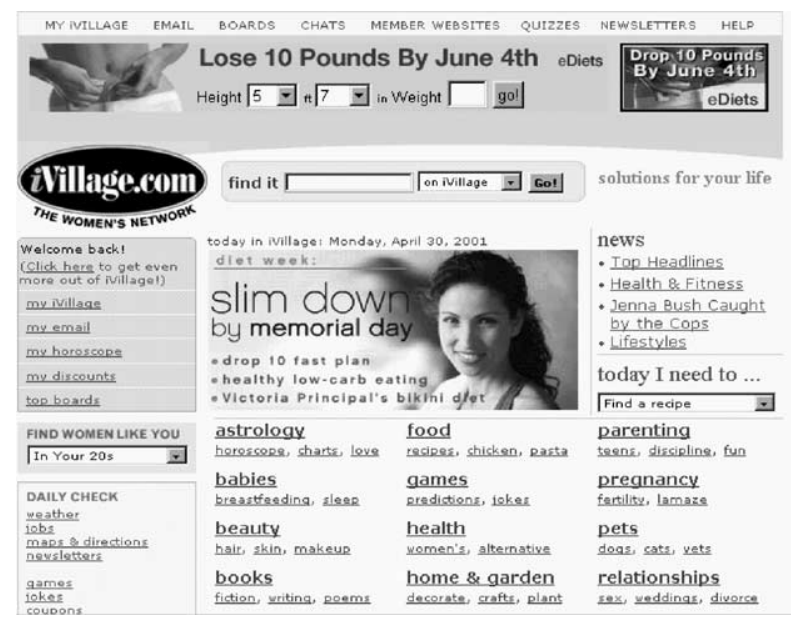

Fig. 2. <http://iVillage.com> Starting Node. 
the Web is a space for everyone, even women. Without questioning why women need their own "Web for women," this marking of women's needs as specialized implies that the rest of the Web, the more neutral Web, is by default a "Web for men." Students did not necessarily question the need for such web sites or by contrast, what a nonspecialized, neutral web site might be like. Ultimately, those specialized web-based communities can help to rationalize the idea that the Web does offer something for everyone as if equality is comparable to equity.

This perception of the Web as inclusive is further validated by the students' assumption that the Web held the answers to their questions-even answers to the particular questions that Elizabeth posed about the online communities. Elizabeth stated that "students were very frustrated when they would go to a search engine and type in 'Why do people use chatrooms?' and they would get a scatter shot result rather than an answer to the question" (personal interview, Dec. 13, 1999). The student belief that the Web both contained information to answer all questions and also represented all people confounded students' abilities to articulate critical edentities for themselves and to create sophisticated critiques of the online communities with which they were engaged.

In completing the technology-ranking exercise, Elizabeth circled a "9" to represent her theoretical commitment to critical theories of technology and a "7" to represent her practical deployments. When I asked her about the difference, she commented:

I think a lot of times I have pushed critical theories of technology aside in the classroom so that I can explain this is how you do it [use the technology in some way]. I did want them to critically consider email and hypertext, but when it came time to subscribe to the listserv that skill became more of a priority. There is that discrepancy. I am theoretically committed to critical theories but practically I end up making sacrifices. I think my theoretical commitment, because it is theoretical, will always remain a number or two higher, but as I learn to teach technologies and students come into my classroom with more of a grounding in technology, I will be able to be more critical. (personal interview, Dec. 13, 1999)

Elizabeth and Kris expressed the same sentiments about having goals of creating critical spaces for critiques of technology in the classroom and needing to help students learn the technologies so that they can participate in the course. The students, themselves, whether technology experts or novices, were compelled to make the most of the small class size and of the instructor's individual attention as they learned more about technologies-Web, email, chatspaces, word processing, and so on-as tools. They rationalized this instrumentalist view by believing that these skills would set them apart from "low-tech" peers.

\subsection{Sam's negotiation of the Web as a global village}

In Sam's course, issues of otherness and global village also figured quite prominently. Unlike Kris and Elizabeth's approach to constructing the Web and technology as the themes for the courses, Sam chose to have students explore the idea of "free speech." As outlined in his course materials, he designed a pedagogy to engage students in the exploration of these two questions posted on his course web page: (1) "What does this freedom [free speech] supposedly entail and what are the effects of having just such a freedom?" and (2) "Just how 
'free' is free speech?' (1999) Sam developed the course to get at these issues, and the Web figured prominently, perhaps more than he even anticipated, in students' pursuit of these questions. Sam denoted the prominence of the Web in his class during our first interview when he explained:

since my course is focused upon free speech and the First Amendment, we [he and the students] really had to grapple with the ways in which the Web and the technology, which the WWW represented, problematized the "normal" boundaries of what constituted free speech versus regulated speech. Since obviously the WWW as a space has been largely unregulated, we arrived with a lot of ethical questions about permissible versus non-permissible sites and fuzzy boundaries between the two. (personal interview, Oct. 5, 1999)

Sam articulated how the Web brought further complications to the already complex issue of free speech. The pursuit of these questions, however, did not fend off assumptions about the ease of the Web or one's equal opportunity to participate in it. In fact, students assumed that the "deregulated" status of the Web was attributable to its "naturally" democratizing presence.

Like Kris and Elizabeth, Sam experienced a tension between the "high-tech" and "low-tech" representations of technology. For him, this discrepancy came to the forefront during a web authoring assignment where students were asked to create a web resource page on an aspect related to free speech. One of Sam's technologically prepared students completed his web page almost a week in advance of his classmates and explained to Sam that "I cranked my page out this weekend, and it was easy. Is it really worth $15 \%$ of my grade?" From his comments, this student demonstrated his confidence in his web skills, taking on the edentity of technology expert.

Because of his perceived success with the high-tech assignment, this student demonstrated further confidence that the upcoming research paper with its low-tech or, for him, "no tech" status would be even easier to compose. This perception went unchallenged as his fellow students busily worked to create their pages and learn aspects of HTML, web editing, web design, and FTPing. In fact, during this 50-minute class, other students with less apparent web skills continued to consult with Sam, asking almost 25 questions of clarification about links, layout, copyright on images, file transfer, and publishing their pages. Of all the students in Sam's class, it was easy to see and hear the three students who had high-tech confidence in their web skills: Their comments ranged from the "ease" of web development to the "bad design" of other students' pages to the HTML editors being "crap." The construction of the Web as an "easy" place to construct one's presence, and thus join the global community, was reflected in the comments of students in Sam's class. Even students actively engaged in the development of their pages felt that learning the skill was all that prevented them from being a part of the "global village."

In positioning himself on the technology-ranking exercise, Sam chose an " 8 " to represent his theoretical commitment to critical theories of technology and " 6 " to represent his practical instantiations of those commitments. When asked about the difference in his ranking, he revealed the following:

I think that I have a good theoretical understanding of a critical methodology or critical view of technology in the computer classroom, and I am committed to that. Yet, I don't think that 
my practical ability allows me to implement that on the same level because I don't have the facility with the technology at the practical level. (personal interview, Dec. 13, 1999)

Thus, Sam expressed concern with teaching technology critically, much like his colleagues Kris and Elizabeth, but he also addressed a discrepancy between his technology skills (not necessarily those of students in his class) and his theoretical background in critical theories of technology. Similar in his response to the participants in Elizabeth Klem and Charles Moran's (1992) study of instructors new to teaching in the computer classroom, Sam identified his need to understand the practical applications of technology prior to teaching it critically to students in his class. This sense of his development as a technology user was brought to Sam's attention when, as he explained it as follows:

my own students knew more about web publishing and HTML coding and general web page design so with respect to just general practical knowledge of computer hardware and software, I don't feel comfortable matching these two different rankings. (personal interview, Dec. 13, 1999)

The tone in Sam's class and some of the ways the Web was constructed made him question his own knowledge, his own edentity - despite having created a web syllabus and calendar for his course, incorporated web research and authoring, used a web-interfaced chatspace and MOO, and provided access to his past web pages on critical race theory. In many ways, Sam inhabited the edentity of "outsider" in terms of his technological skills, a particularly unfortunate analysis considering the support he offered to students in his class and his demonstrated technology knowledge. From such comments, it is apparent that the high-tech and low-tech perceptions of technology — and how those affect our preparation to teach in computer classrooms-influence not only students' perceptions of technology but also instructors' perceptions of how technology issues need to be approached in the classroom.

\section{Rearticulating the edentity of the computer composition instructor through contextualized teacher training}

Selfe (1992) urges us to examine our computer composition teaching practices and contends that we must see ourselves as life-long learners, researchers, and architects of classroom spaces (p. 30). This articulation of the computer composition instructor contextualizes instructional practices and argues that those practices must be informed by social, cultural, and economic inquiries. Technology learning is cast not as developing a set of skills but rather as contextualizing technologies and developing training that speaks to that contextualization (Hawisher \& Selfe, 1991; Kaplan, 1991; Sommers, 1992). That is, Selfe's discussion clearly situates the role of the computer compositionist in a complex set of circumstances where technological competency includes practical, theoretical, ideological, and material understandings of the roles that technology plays in the composition classroom.

Based upon my experiences developing teacher training and my work in this study, I better understand the challenge to build such teacher training practices. In their extensive study on teacher transitions from the traditional to the computer classroom, Mike Palmquist, Kate Kiefer, James Hartvigsen, and Barbara Goodlew (1998) recommends a range of strategies to make 
that shift more productive such as "set clear ground rules, set a clear routine for the opening of class sessions, emphasize strategies for learning names, etc." and categories such as "Getting Started with the Semester: Taking Advantage of Computer Tools" (pp. 158-160). The potential limitation in Palmquist, Kiefer, Hartvigsen, and Goodlew's advice, however, is also the flaw in the mentoring I helped to establish in the fall during my study. That is, rather than providing explicit support to challenge cultural narratives of the Web or any technology, the mentoring focused on practical integrations of technology. Although necessary and useful to learn technological skills and pedagogical applications, I believe a more contextualized approach to web-based teaching would have offered instructors the means to challenge narratives of the Web. Thus, I propose three ways of rearticulating more complex edentities in the web-based classroom: historical inquiry, ideological inquiry, and resistant material instantiations of technology.

\subsection{Historical inquiry}

Historical inquiry into web-based technologies is one means of contextualizing the Web. Rather than seeing herself subject to the demands of the web-based classroom and finding herself "choosing" between teaching a critical approach and teaching a technological skill, the instructor as critical agent can define and redefine the boundaries of web use through sustained historical inquiry on the integration of technology in her intellectual and pedagogical life. Historical inquiry is both a personal historicizing of web use and a historicization of the development of certain web-based technologies. As an instructor explicitly maps out histories of her web-based pedagogical practices, she reveals ways of intervening in her technological instantiations. These mappings can take a variety of forms, from reflective essays and web pages to visual maps outlining certain practices, but they must be shared and exchanged with a community of practitioners. Already recommended to help students develop critical technological literacy (Blakely Duffelmeyer, 2000; Takayoshi, 1996), this dual form of history making can help an instructor reveal the tensions between meeting certain professional and pedagogical goals while offering critical frameworks for technological engagement.

\subsection{Ideological inquiry}

In addition to sharing historical inquiries as part of teacher training, ideological inquiry can help an instructor develop critical agency. Although historical inquiry is recording changes to pedagogical and technological instantiations across time, ideological inquiry as a part of teacher training can help open up questions about how and why a certain pedagogical and technological experience occurs as it does and what the consequences of such an experience are for those involved. Rather than assuming that the technological and pedagogical circumstances are always in line with one another, an instructor considers the larger cultural meanings implicated in her use of web-based technologies, and how those technologies, in turn, influence pedagogical possibilities. Getting at the ideological implications of web-based materials can allow an instructor to develop a more complex way of approaching the incorporation of web-based technologies in her classroom and raise issues that otherwise might remain unexplored. 


\subsection{Resistant material instantiations}

To further contextualize teaching practices, historical and ideological inquiries can be complemented by resistant material instantiations of technology. These resistant material instantiations reassert the technological context as primary in determining possible uses for that technology. In other words, the environment, persons, and situations affect the technological integration rather than placing primary emphasis on the technology itself. Although the scope of these acts may be small, their impact on the learning opportunities for an instructor and students can be far reaching. Thus, in the move to develop critical agency, the instructor needs a better awareness of the underlying logics of the web-based technology. This sort of understanding can be developed in a variety of ways: One strategy is learning the web-based skills and critiquing those skills while they are being learned rather than after they have been learned.

\subsection{Response to local situation}

Lastly, contextualized teacher training needs to respond to the needs of an instructor within her local context. The local situation of a particular institution might mean that certain teaching constraints in terms of resources and respect need to be taken into account in the development or revision of teacher training. In terms of resources, an instructor might find herself challenged by working with outdated technological systems (Hartley, Schendel, \& Neal, 1999), and in terms of respect, an instructor might be subjected to attitudes that technological work is merely about skill rather than intellectual development (see Day, 2000; Gruber, 2000; Rickly, 2000 for a startling look at this situation). Working within and sometimes against the structures of a particular system is one of the greatest challenges of the critical computer compositionist.

Decontextualized and reductive views on the Web and its role in our classrooms can leave instructors and students with little opportunity to critically engage and even potentially shift the ways that web-based technologies limit their edentities. Striving to contextualize web-based technology can lead to a renegotiated space in the electronic classroom, a space where more equitable relationships can be established and nurtured. Through historical inquiry, ideological inquiry, and resistant material instantiations, the computer compositionist can develop a more complex edentity than the one offered by cultural narratives of technology. With a commitment to such praxis, the computer compositionist can rearticulate an edentity marked by possibility for critique and change.

\section{Notes}

1. Edentity is my term for electronic identity. This identity, however, is not equitable to an online persona. Rather, an edentity is created through technological experiences including interactions with technology as well as negotiation of cultural constructions of technology. Our edentities represent the possible subject positions we can inhabit in relationship with our technological culture.

2. Because of articulation's complexity and flexibility, it has been deployed as a means to question and rearticulate such areas of our cultural experience as aesthetics, race, nature, hypertext, corporate web pages, and communication practices (Hall, 1985, 1989; 
Haraway, 1995; Jameson, 1991; Johnson-Eilola, 1993, 1997a, 1997b; Kimme Hea, 1999; Slack, 1989).

3. Melinda Turnley is currently an assistant professor in the Division of Rhetoric and Composition at The University of Texas at Austin. Her research interests include critical theories of media and technology, teacher training, and writing pedagogy.

4. I have used pseudonyms to protect the identity of the participants.

5. The interview questions were pilot tested with a colleague teaching in a computer classroom who had no involvement in the mentoring group. I also shared drafts of the interview questions with Irwin Weiser and Johndan Johnson-Eilola.

6. I piloted these ranking exercises with the same colleague who volunteered to test my interview questions, and I shared drafts of the exercises with Johndan Johnson-Eilola.

7. When I refer to the instructors' web-based materials, I do not provide URLs in order to maintain their anonymity.

8. For an analysis of <http://iVillage.com>, see Michelle Eble and Robin Breault's "The Primetime Agora: Knowledge, Power, and "Mainstream" Resource Venues for Women Online" in this edition.

\section{Acknowledgments}

Special thanks to my participants and my colleagues Melinda Turnley, Susan Swan, and Thomas Miller for their comments on drafts of this article.

Amy C. Kimme Hea is an assistant professor in the Rhetoric, Composition, and Teaching of English program at University of Arizona. Her research interests include web-based teaching and learning, teacher training, and professional writing theory and practice. She has published on articulation theory and methodology in the international journal, Educare/Educare and has an essay on the relationship of academic and corporate web development and use in Working with Words and Images: New Steps in an Old Dance, edited by Nancy Allen.

\section{References}

Blakely Duffelmeyer, Barbara. (2000). Critical computer literacy: Computers in first-year composition as topic and environment. Computers and Composition, 17, 289-308.

Day, Michael. (2000). Teachers at the crossroads: Evaluating teaching in electronic environments. Computers and Composition, 17, 31-40.

Deleuze, Félix, \& Guattari, Gilles. (1987). A thousand plateaus: Capitalism and schizophrenia (Brian Massumi, Trans.). Minneapolis: University of Minnesota Press.

DeWitt, Scott Lloyd. (1997). Out there on the Web: Pedagogy and identity in face of opposition. Computers and Composition, 14, 229-243.

Feenberg, Andrew. (1991). Critical theory of technology. New York: Oxford University Press. 
Feenberg, Andrew. (1995a). Alternative modernity: The technical turn in philosophy and social theory. Los Angeles: University of California Press.

Feenberg, Andrew. (1995b). Subversive rationalization: Technology, power, and democracy. In Andrew Feenberg \& Alastair Hannay (Eds.), Technology \& the politics of knowledge (pp. 3-22). Indianapolis: Indiana University Press.

Feenberg, Andrew. (1999). Questioning technology. New York: Routledge.

Gillette, David. (1999). Pedagogy, architecture, and the virtual classroom. Technical Communication Quarterly, $8(1), 21-36$.

Grossberg, Lawrence. (1992). We gotta get out of this place: Popular conservatism and postmodern culture. New York: Routledge.

Gruber, Sibylle. (2000). Technology and tenure: Creating oppositional discourse in an off-line and online world. Computers and Composition, 17, 41-56.

Hall, Stuart. (1985, June). Signification, representation, ideology: Althusser and the poststructuralist debates. Critical Studies in Communication, 2, 91-114.

Hall, Stuart. (1986). On postmodernism and articulation: An interview with Stuart Hall. Journal of Communication Inquiry, 10(2), 45-60.

Hall, Stuart. (1989). Ideology and communication theory. In Lawrence Grossberg, Brenda Dervin, Barbara J. O'Keefe, \& Ellen Wartella (Eds.), Rethinking communication vol. 1: Paradigm issues (pp. 40-52). Newbury Park, CA: Sage.

Haraway, Donna. (1985). A manifesto for cyborgs: Science, technology, and socialist feminism in the 1980s. Socialist Review, 80, 65-105.

Haraway, Donna. (1995). Situated knowledges: The science question in feminism and the privilege of partial perspective. In Andrew Feenberg \& Alastair Hannay (Eds.), Technology and the politics of knowledge (pp. 175-194). Indianapolis: Indiana University Press.

Haraway, Donna. (1997). Modest_Witness@Second_Millennium.FemaleMan_Meets_OncoMous: Feminism and technoscience. New York: Routledge.

Hartley, Cecilia, Schendel, Ellen, \& Neal, Michael R. (1999). Writing (ONLINE) space: Composition webware in Perl. Computers and Composition, 16, 359-370.

Hawisher, Gail E., \& Selfe, Cynthia L. (1991). The rhetoric of technology and the electronic writing class. College Composition and Communication, 42, 55-65.

Hawisher, Gail E., \& Sullivan, Patricia A. (1999). Fleeting images: Women visually writing the Web. In Gail E. Hawisher \& Cynthia L. Selfe (Eds.), Passions, pedagogies, and 21 st century technologies (pp. 268-291). Logan, UT: University of Utah Press.

Heba, Gary. (1997). HyperRhetoric: Multimedia, literacy, and the future of composition. Computers and Composition, 14, 19-44.

Jameson, Fredric. (1991). Postmodernism: Or, the cultural logic of late capitalism. Durham, NC: Duke University Press.

Johnson-Eilola, Johndan. (1993). Control and the cyborg: Writing and being written in hypertext. Journal of Advanced Composition, 13, 381-399.

Johnson-Eilola, Johndan. (1997a). Nostalgic angels: Rearticulating hypertext writing. Norwood, NJ: Ablex.

Johnson-Eilola, Johndan. (1997b). Wild technologies: Computer use and social possibility. In Stuart Selber (Ed.), Computers and technical communication: Pedagogical and programmatic perspectives (pp. 97-128). Greenwich, CT: Ablex.

Kaplan, Nancy. (1991). Ideology, technology, and the future of writing instruction. In Gail E. Hawisher \& Cynthia L. Selfe (Eds.), Evolving perspectives on computers and composition studies: Questions for the 1990s (pp. 11-42). Urbana, IL: NCTE and Computers and Composition Press.

Kimme Hea, Amy C. (1999). Exploring articulation as a methodology: An articulation of the corporate presence in relationship to scholarship. Educare/Educere, 5(7), 41-52.

Klem, Elizabeth, \& Moran, Charles. (1992). Teachers in a strange LANd: Learning to teach in a networked writing classroom. Computers and Composition, 9, 5-22.

Laclau, Ernesto. (1977). Politics and ideology in Marxist theory: Capitalism-Facism_Populism. London: Atlantic Highlands: Humanities Press. 
Laclau, Ernesto, \& Mouffe, Chantal. (1985). Hegemony and socialist strategy: Towards a radical democratic politics. London: Verso.

Lather, Patti. (1991). Getting smart: Feminist research and pedagogy with/in the postmodern. New York: Routledge.

Latour, Bruno. (1992). Where are the missing masses? The sociology of a few mundane artifacts. In Wiebe Bijker, Thomas Hughes, \& Trevor Pinch (Eds.), Shaping technology/building society: Studies in sociotechnical change (pp. 225-258). Cambridge, MA: MIT Press.

Latour, Bruno. (1993). We have never been modern (Catherine Porter, Trans.). Cambridge, MA: Harvard University Press.

Moran, Charles. (1998). From a high-tech to a low-tech writing classroom: "You can't go home again". Computers and Composition, 15, 1-10.

O'Sullivan, Mary F. (1999). Worlds within which we teach: Issues for designing World Wide Web course material. Technical Communication Quarterly, 8(1), 61-72.

Pagnucci, Gian S., \& Mauriello, Nicholas. (1999). The masquerade: Gender, identity, and writing for the Web. Computers and Composition, 16, 141-151.

Palmquist, Mike Kiefer; Kate, Harvigsen, James; \& Goodlew, Barbara. (1998). Transitions: Teaching writing in computer-supported and traditional classrooms. Greenwich, CT: Ablex.

Rickly, Rebecca. (2000). The tenure of the oppressed: Ambivalent reflections from a critical optimist. Computers and Composition, 17, 19-30.

Schneider, Suzanne P., \& Germann, Clark G. (1999). Technical communication on the Web: A profile of learners and learning environments. Technical Communication Quarterly, 8(1), 37-48.

Selfe, Cynthia L. (1992). Preparing English teachers for the virtual age: The case for technology critics. In Gail E. Hawisher \& Paul LeBlanc (Eds.), Re-imagining computers and composition: Teaching and researching in the virtual age (pp. 24-42). Portsmouth, NH: Boynton/Cook.

Selfe, Cynthia L. (1999a). Lest we think the revolution is a revolution: Images of technology and the nature of change. In Gail E. Hawisher \& Cynthia L. Selfe (Eds.), Passions, pedagogies, and 21st century technologies (pp. 292-322). Logan, UT: University of Utah Press.

Selfe, Cynthia L. (1999b). Technology and literacy: A story about the perils of not paying attention. College Composition and Communication, 50, 411-436.

Slack, Jennifer D. (1989). Contextualizing technology. In Brenda Dervin, Lawrence Grossberg, Barbara J. O'Keefe, \& Ellen Wartella (Eds.), Rethinking communication vol. 2: Paradigm exemplars (pp. 329-345). London: Sage.

Slack, Jennifer D. (1996). The theory and method of articulation in cultural studies. In David Morley \& Kuan-Hsing Chen (Eds.), Critical Dialogues in Cultural Studies (pp. 112-127). London: Routledge.

Sommers, Elizabeth. (1992). Political impediments to virtual reality. In Gail E. Hawisher \& Paul LeBlanc (Eds.), Re-imagining computers and composition: Teaching and researching in the virtual age (pp. 43-57). Portsmouth, NH: Boynton/Cook.

Takayoshi, Pamela. (1996). Writing the culture of computers: Students as technology critics in cultural studies classes. Teaching English in the Two-Year College, 23(3), 198-204.

Takayoshi, Pamela, Huot, Emily, \& Huot, Meghan. (1999). No boys allowed: The World Wide Web as a clubhouse for girls. Computers and Composition, 16, 89-106.

Watkins, Steve. (1996). World Wide Web authoring in the portfolio-assessed, (inter)networked composition course. Computers and Composition, 13, 219-230. 